\title{
O CEJA como Lugar de Memórias
}

\author{
CEJA as a Place of Memories \\ CEJA como Lugar de Recuerdos
}

Recebido: 19/07/2021 | Revisado: 25/07/2021 | Aceito: 26/07/2021 | Publicado: 02/08/2021

\author{
Samya Karla Lopes de Oliveira \\ ORCID: https://orcid.org/0000-0003-1615-4445 \\ Universidade de Cuiabá, Brasil \\ E-mail: sa40lopes@gmail.com \\ Cilene Maria Lima Antunes Maciel \\ ORCID: https://orcid.org/0000-0003-4606-802X \\ Universidade de Cuiabá, Brasil \\ E-mail: cilenemlamaciel@gmail.com
}

\begin{abstract}
Resumo
Este estudo apresenta um recorte de pesquisa realizada no Programa de Pós-graduação, Mestrado em Ensino, PPGEN/UNIC/IFMT, análise acerca da organização pedagógica em trimestres por área de conhecimento implantada nos CEJAS Centros de Educação de Jovens e Adultos em Mato Grosso por meio de memórias e narrativas de estudantes e professores que vivenciaram a proposta entre os anos de 2008 a 2016, como forma de criar arquivos, organizar as ações realizadas, pois, estas intervenções são produzidas socialmente. No entanto, a aceleração do tempo nos faz esquecer ou desconsiderar o passado, sendo necessário alicerçar as memórias coletivas. A Metodologia desta pesquisa se classifica como um estudo qualitativo documental e narrativo considerando que os documentos oficiais deste período são dados iniciais para representar a existência de relembranças (currículo, planejamento e avaliação), bem como, a identificação do papel dos Centros de EJA nas políticas educacionais do Estado. E as narrativas dos participantes representam os registros deste espaço de memórias e representações da cultura escolar. Como resultado evidenciamos que os grupos sociais constroem suas narrativas com base na memória da experiência seja ela por meio da escrita, neste estudo os documentos ou orais presentes nas entrevistas que lamentavelmente tem sido desconsiderada quando se trata elaboração e continuidade de políticas públicas educacionais.
\end{abstract}

Palavras-chave: Educação de jovens e adultos; Ensino; Memórias.

\begin{abstract}
This study presents a research excerpt carried out in the Postgraduate Program, Master in Teaching, PPGEN/UNIC/IFMT, analysis of the pedagogical organization in quarters by knowledge area implemented in CEJAS Centers for Youth and Adult Education in Mato Grosso by through memories and narratives of students and teachers who experienced the proposal between 2008 and 2016, as a way to create files, organize the actions carried out, as these interventions are socially produced. However, the acceleration of time makes us forget or disregard the past, making it necessary to ground collective memories. The methodology of this research is classified as a qualitative documentary and narrative study considering that the official documents of this period are initial data to represent the existence of memories (curriculum, planning and evaluation), as well as the identification of the role of EJA Centers in policies educational institutions of the State. And the participants' narratives represent the records of this space of memories and representations of school culture. As a result, we show that social groups build their narratives based on the memory of the experience, whether through writing, in this study the documents or oral presentations present in the interviews that unfortunately have been disregarded when it comes to the elaboration and continuity of educational public policies.
\end{abstract}

Keywords: Youth and adult education; Memoirs; Teaching.

\section{Resumen}

Este estudio presenta un extracto de investigación realizada en el Programa de Posgrado, Maestría en Docencia, PPGEN / UNIC / IFMT, análisis de la organización pedagógica en trimestres por área de conocimiento implementado en los Centros CEJAS de Educación de Jóvenes y Adultos en Mato Grosso a través de memorias y narrativas de estudiantes y docentes que vivieron la propuesta entre 2008 y 2016, como una forma de crear archivos, organizar las acciones realizadas, ya que estas intervenciones se producen socialmente. Sin embargo, la aceleración del tiempo nos hace olvidar o desconocer el pasado, por lo que es necesario fundamentar la memoria colectiva. La metodología de esta investigación se cataloga como estudio cualitativo documental y narrativo considerando que los documentos oficiales de este período son datos iniciales para representar la existencia de memorias (currículo, planificación y evaluación), así como la identificación del rol de los Centros EJA. en las políticas de las instituciones educativas del Estado. Y las narrativas de los participantes representan los registros de este espacio de memorias y representaciones de la cultura escolar. Como resultado, mostramos que los grupos sociales construyen sus narrativas a partir de la memoria de la 
experiencia, ya sea a través de la escritura, en este estudio los documentos o presentaciones orales presentes en las entrevistas que lamentablemente han sido desatendidas en lo que respecta a la elaboración y continuidad de políticas públicas educativas.

Palabras clave: Educación de jóvenes y adultos; Memorias; Enseñando.

\section{Introdução}

Este artigo tem como abordagem principal a memória enquanto elemento essencial para compreendermos a organização pedagógica em trimestres por área de conhecimento implantada nos CEJAS - Centros de Educação de Jovens e Adultos, em Mato Grosso no ano de 2008, como experiências sociais e de lutas cotidianas. Conforme Simson (2018, p.1), memória é a capacidade humana de deter fatos e conhecimentos do passado e retransmiti-los às novas gerações por meio de diferentes suportes empíricos (voz, música, imagem, textos etc.).

Também se constitui de acontecimentos vividos pela pessoa ou pelo grupo à qual ela pertence. Assim, estes "lugares" são essenciais para uma sociedade que tem abandonado os referenciais históricos, e tem deixado ao esquecimento o seu patrimônio cultural (Silva; Ruckstadter, 2013, p. 9). Para Teixeira (2015, p. 4), as lembranças são importantes registros vividos que partem e perpetuam com referências e paisagens para um constante retorno aos idos, trazendo em si os mais diversos sentimentos documentados e expressados em narrativas.

As iniciais menções "nascem e vivem do sentimento não espontâneo nas coletividades atuais, que é preciso criar arquivos, organizar celebrações, manter aniversários, notariar atas; porque estas operações não são naturais", pois a aceleração do tempo nos faz esquecer ou desconsiderar o passado. (Nora, 1993, p. 7). São espaços onde presenciamos o momento histórico em que vivemos no limite entre o que éramos e o que somos. Sendo assim, entende-se por memória a construção feita no presente das experiências ocorridas anteriormente que está contida no saber adquirido ou naquilo que já é sabido. (Silva; Ruckstadter, 2013, p. 9).

Tradicionalmente as escolas são vistas como lugares com escassez de registros, exceto aqueles pela útil burocracia de datas, nomes, notas, relatórios de avaliação de aprendizagem, leis e resoluções normativas, entre outros. No entanto, ela também é um rico espaço de memória que muitas vezes fica escondido pela cultura do funcionamento das atividades colegiais no presente que algumas vezes desconsidera as ações que já foram realizadas ou os conhecimentos prévios existentes. E que pode ser objeto para pesquisa nas ciências sociais.

Logo, o recorte de pesquisa apresentado, busca a partir das análises de documentos oficiais, registros escritos, fotografias e entrevistas de professores e estudantes que estiveram envolvidos na organização pedagógica em trimestres por área de conhecimento nos CEJAS em Mato Grosso entre os anos de 2008 a 2016, constituir parte da memória coletiva deste lugar. Segundo Bognar (2019, p. 211), esta era a proposta inicial, visto que os referidos espaços passaram por algumas mudanças dinâmicas de ensino até ser retirada em 2017. Caracterizando como relembranças e narrações de histórias e que, por conseguinte produziram diálogos e aquisições.

Diferente das demais escolas que ofertam a EJA - Educação de Jovens e Adultos, os Centros, conforme a ROP Regra de Organização Pedagógica, documento elaborado pela Secretaria de Estado de Educação (SEDUC, 2013), são criados em Mato Grosso para constituir identidade própria a modalidade, ofertando configurações diferenciadas de estudo que relacionassem a educação formal e informal ao mundo do trabalho e ao longo da vida, reconhecendo as especificidades do público e dos diferentes tempos e espaços formativos.

Para Le Goff (2003), a memória é um elemento eficaz do que destacamos pela individualidade ou coletivamente, sendo uma procura de atividades básicas das pessoas e das sociedades de hoje. Sob este aspecto, Haddad; Di Pierro (2000, p. 108), destaca que, a educação de jovens e adultos sempre compreendeu um conjunto muito diverso de processos e práticas 
relacionadas à aquisição ou ampliação de conhecimentos básicos, de competências técnicas e profissionais ou de habilidades socioculturais, no entanto, o que tem sido priorizado são os interesses políticos e econômicos.

E neste conjunto diverso que surge em Mato Grosso, os CEJAS, cuja a proposta era a organização pedagógica em trimestres por área de conhecimento prevista nas OCDE - Orientações Curriculares das Diversidades Educacionais/SEDUC (2010, p. 214), salientando que ela propiciaria uma flexibilidade que não desvinculava do compromisso com a legislação vigente, pois os educandos tinham claros quais os horários de estudos, conforme a LDB - Lei de Diretrizes e Bases $\mathrm{n}^{\circ}$ 9394//96, no entanto respeitando o tempo de cada um.

A história representa uma configuração que de certo modo referenda teoricamente a política pública educacional, principalmente na perspectiva de oportunizar aqueles que não tiveram acesso à escolarização no momento adequado. Podendo ser vista como uma evocação coletiva da modalidade, pois, significa a base de existir, da identidade desta. Entretanto, seguindo Vasconcelos e Araújo (2016), ela também apresenta de um lado rupturas, posses e revoluções, e outro amores, paixões, esperanças e possibilidades.

Em alguns casos, a memória passa a ser o consolo de perdas irreparáveis, como se quisesse repor a alegria do convívio roubado pela força bruta. É nesse caso que os cortes podem caracterizar um passado imobilizado ou um presente esperado; como se o tempo parasse para registrar um determinado acontecimento que, na realidade, foi visto por um conjunto de atores, integrantes de uma determinada realidade social, os quais, em momentos históricos, também determinados, apresentavam-se como universais. (Vasconcelos; Araújo, 2016).

Sem ela, não temos passado, ela nos permite a relação do corpo presente com aquilo que já foi vivido e ao tempo, interfere no processo 'atual' das representações, por meio dela, o que passou não só vem à tona das águas presentes, misturando com as percepções imediatas. Bosi (1994, p. 9). Esse estudo tomou como ponto de partida pesquisas realizadas no âmbito da memória coletiva, principalmente as escolares, EJA e os CEJAS em Mato Grosso. Dentre elas destacamos autores como: Haddad; Di Pierro (2000), Bignarde (2013), Bognar (2019), entre outros.

\section{Metodologia}

Inicialmente buscamos fundamentos a partir da revisão de literatura sobre as direções teórico-metodológicos da pesquisa qualitativa e os conceitos de memória enquanto objeto de investigação. Segundo Kruger (2013), a pesquisa qualitativa é ampla e com diferentes abordagens da realidade social, porém, possui entre suas características a compreensão como princípio epistemológico fundamental para busca de reconstrução das perspectivas dos atores sociais, das situações, normas e regras culturais.

Para o estudo da organização pedagógica em trimestres por área de conhecimento implantada nos CEJAS, em 2008, adotamos a estratégia metodológica qualitativa, utilizando-se a técnica de levantamento de literaturas científicas e documental destacada Marconi; Lakatos (2019), que os documentos podem ser escritos ou não, e que instituem o que se denomina de informações primárias. Diferenciando da bibliográfica pela natureza das origens, sendo material que ainda não recebeu tratamento analítico, ou que pode ser reelaborado de acordo com os objetivos da pesquisa.

Tanto a investigação bibliográfica como a documental estarão ligadas inicialmente a um caráter exploratório no qual buscamos para realizar as análises da proposta citada acima, que resultará constituição da memória coletiva. Ressaltamos também que os documentos selecionados foram aqueles elaborados pela SEDUC, como também registros produzidos pelas instituições: Professora Almira de Amorim Silva em Cuiabá e Antonio Casagrande em Tangará da Serra. Posteriormente realizamos entrevistas narrativas com 12 professores e 16 estudantes das unidades escolares citadas, dividindo a pesquisa entre documental e narrativa. 
Dentre os documentos produzidos pela Secretaria de Estado de Educação selecionamos e analisamos os seguintes: OCDE (SEDUC, 2010), descreve de maneira suscita a proposta pedagógica dos centros no Estado. A Regra de Organização Pedagógica ROP (SEDUC, 2013) que define os critérios de funcionamentos dos Centros, entre outros. Após aprovação de projeto no conselho de ética, onde consta em anexos as autorizações de dois CEJAS lócus desta pesquisa, coletamos dados registros escritos produzidos pelas instituições sendo eles: PPP - Projeto Político Pedagógico e Agenda Institucional.

Devido a pandemia do Convid-19 em que foi determinado isolamento social num primeiro momento, bem como a suspensão das aulas presenciais, utilizamos e-mail e aplicativo WhatsApp para diálogos com as instituições e envio dos documentos citados acima. Na seleção para análise de dados, optamos pela última estruturação do PPPs, da unidade de ensino Antonio Casagrande (2014) e Professora Almira de Amorim (2015), embora saibamos que eles são reelaborados anualmente, porém, no que se refere a organização pedagógica em trimestres por área de conhecimento nos CEJAS, não houve alterações na estrutura da proposta entre os anos de 2008 a 2016.

Em outros momentos previamente agendados como o envio das autorizações para concessão de entrevistas e gravação, também via aplicativo de WhatsApp e e-mails definindo a escola para entrega do TCLE - Termo de Consentimento Livre e Esclarecido, bem como gravação de voz, uso de som e imagem. Foram entrevistados um total de 28 participantes, sendo: 12 professores (dois para cada área de conhecimento) e 16 estudantes do ensino médio que estiveram envolvidos com a proposta pedagógica existente entre os anos de 2008 a 2016.

A pesquisa narrativa definida por Clandinin e Connely (2000), como uma forma de entender a experiência em um processo de colaboração entre o pesquisador e o pesquisando, caracterizado como um método, conforme Boldarine (2010) que considera como um de seus instrumentos a subjetividade individual, oferecendo a oportunidade de dar voz a professores e estudantes que muitas vezes não são ouvidos ou possuem um pequeno espaço para expor-se. E ainda:

Pesquisa narrativa é uma abordagem qualitativa que se apresenta como alternativa a métodos de pesquisas tradicionais. Partindo da compreensão de experiência como histórias vividas, narradas, que se estrutura na intencionalidade de entender e interpretar as dimensões pessoais e humanas para além de esquemas fechados, recortados e quantificáveis. (Mariani; Mattos, 2012).

$\mathrm{Na}$ realização das entrevistas, elaboramos previamente um roteiro de perguntas abertas, conforme a temática da pesquisa, cujo o intuito foi coletar as narrativas de memórias de professores e estudantes, que aconteceu da seguinte forma: via aplicativo de sala virtual Jitsi Meet, cuja a gravação é sem custo, e também na escola atendendo os protocolos de biossegurança, mantendo distanciamento social, uso de máscara e álcool em gel.

De acordo com Muylaert et al. (2014), as entrevistas narrativas se caracterizam como instrumentos não estruturados, visando a profundidade, de aspectos específicos, a partir das quais emergem histórias de vida, tanto do entrevistado como as entrecruzadas no contexto situacional. Esse tipo de abordagem visa encorajar e estimular o sujeito informante a contar algo sobre algum acontecimento importante de sua vida e/ou do contexto social. Tendo como base a ideia de reconstruir fatos a partir do ponto de vista das narrativas.

(...) entrevista narrativa considera-se que nossa memória é seletiva, lembramos daquilo que "podemos" e alguns eventos são esquecidos deliberadamente ou inconscientemente. Nessa perspectiva, o importante é o que a pessoa registrou, sua experiência. Dessa forma, são consideradas as representações de um determinado tempo, espaço e contexto sócio histórico. Não se tem acesso direto às experiências dos outros, se lida com as leituras dessas experiências. (Muylaert et al., 2014). 
Research, Society and Development, v. 10, n. 9, e55310918419, 2021

(CC BY 4.0) | ISSN 2525-3409 | DOI: http://dx.doi.org/10.33448/rsd-v10i9.18419

Quanto as análises consideramos os dados referente a organização pedagógica em trimestres por área de conhecimento implantada nos CEJAS em Mato Grosso, primeiramente os documentos que registram esta proposta e posteriormente as entrevistas com 12 professores e 16 estudantes do ensino médio. Para Muylaert et. al. (2014), a forma oral de se comunicar atribuir outros sentidos ao tempo vivido, ou seja, a narrativa contribui com a construção histórica da realidade.

\section{Resultados e Discussão}

\subsection{Os Centros de Educação de Jovens e Adultos: Memórias}

Os Centros de Educação de Jovens e Adultos foram criados em Mato Grosso por meio de decreto estadual № 1.123 , de 28 de janeiro de 2008, com a finalidade que a modalidade tivesse o seu espaço de identidade, pois, anteriormente a EJA era atendida apenas no período noturno e com os mesmos professores que atendiam em período diurno crianças e adolescentes. (Pereira e Fonseca, 2001; Ribeiro, 1999). Enquanto que os CEJAS disponibilizavam matriculas nos três períodos proporcionando, segundo suas regras pedagógicas, um avanço no atendimento da proposta da EJA no Estado. (Bignarde, 2013)

Contexto também destacado por Bognar (2019), em que os centros sinalizavam para a construção de um espaço alternativo de atendimento diferenciado e adequado aos sujeitos da EJA, garantindo a oferta em todos os turnos, com finalidade de reduzir a evasão escolar, respeitando os diferentes tempos e espaços de aprendizagem dos educandos e suas especificidades.

Segundo, a ROP (SEDUC, 2013), este funcionamento integral era vinculado a um calendário escolar padrão a todos os CEJAS onde o ano letivo era organizado em 3 trimestres, abrangendo as quatro áreas de conhecimento. Cada trimestre computava o mínimo de 67 dias para o desenvolvimento do ensino, porém no final do ano deveria ser totalizado os 200 dias letivos previstos em legislação. Também havia conforme o documento citado, uma flexibilidade nas formas de matrículas, apresentamos a seguir imagens que retratam esta realidade educacional.

Figura 1 - Calendário de 2016.

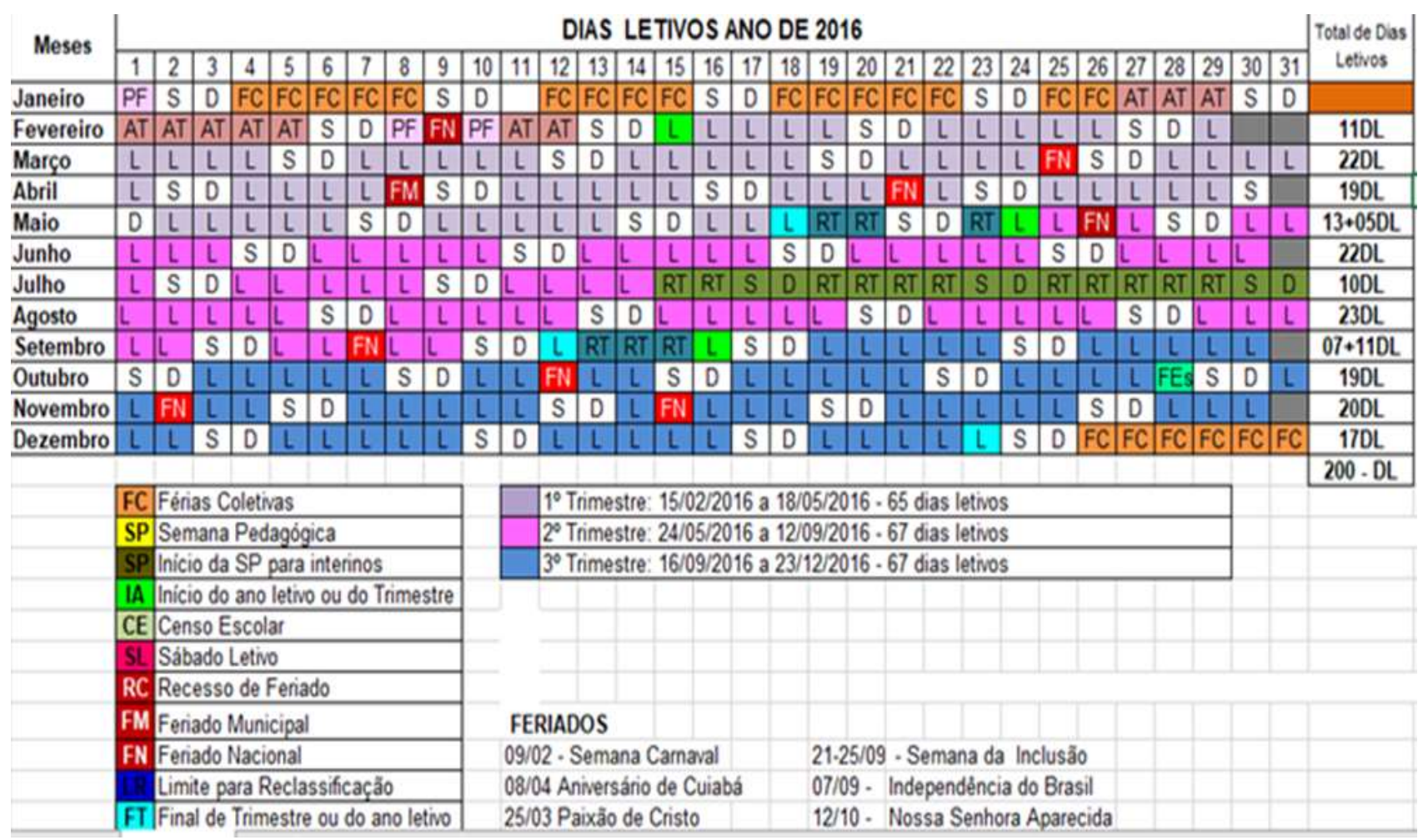

Fonte: CEJA Professora Almira De Amorim Silva, (2016). 
Research, Society and Development, v. 10, n. 9, e55310918419, 2021

(CC BY 4.0) | ISSN 2525-3409 | DOI: http://dx.doi.org/10.33448/rsd-v10i9.18419

Figura 2 - Formas de matrículas nos CEJAS.

SEDUC-MT

ROP - CEJA -POR ÁREAS DE CONHECIMENTO

imferraira

FLEXIBILIDADE NAS FORMAS DE MATRÍCULAS NOS CEJAS

Na forma de oferta por Área de Conhecimento será facultada a matrícula:

1. em mais de uma área de conhecimento do mesmo Ano no trimestre, em turnos diversos, no mesmo CEJA;

2. om apenas uma área por trimestre e por turno, sendo que ao concluir uma ârea de um Ano, o educando deverá matricular-se no trimestre posterior na(s) área(s) nẩo cursada(s) do mesmo Ano;

3. em áreas de conhecimento de dois Anos, sendo que a matricula no Ano posterior terá como pré-requisito a conclusăo com éxito da área da Ano anterior. Ex. $O$ educando é do 10 ano do ensino médió no primeiro trimestre ele cursou com exito a área de Ciências Humanas; no $\underline{2}^{p}$ trimestre ele dispöe de tempo para cursar duas áreas em tumos diferentes. $Q$ CENA naquele trimestre ofertava apenas a área de Linquagens da $1^{\imath}$ Ano no entante estava ofertando a drea de Clências Humanas do $2^{2}$ ano entâo serd permilido matricular-se $e$ cursar em um turno a área de Linguagens do primeiro ano em outro fumo a area de Ceencias Humanas de 2" Ane:

Vale ressaltar que isso poderá acontecer somente mediante exito comprovado devendo o educando, preferencialmente, cursar um Ano completo no ano letivo, sem fragmentaçăo.

4. O aluno oriundo da organizaçăo anual que no ano cursado năo tenha logrado êxito em alguma área, deverâ matricular-se no Ano posterior com aproveitamento de estudos das áreas que obteve aprovaçåo. 0 resultado da avaliaçăo será por ârea;

5. em caso de disponibilidade de tempo poderá matricular-se no trimestre posterior, na mesma área de conhecimento do Ano já cursado. Ex, 으 educando cursou a área de LCT no $1^{0}$ ano no primeiro trimestre. № sequndo trimestre pelo horário do CEJA ele năo tem como cursar outra área do $1 ?$ ano mas, ostava sendo ofertada a área de LCT do $\underline{2}^{\circ}$ ano então é possivel ele cursar a área de LCT no $2^{2}$ ano considerando que iá cursou com éxito essa área no $1^{2}$ ano.

De acordo com essas flexibilidade o educando poderá concluir dois Anos do curso no mesmo ano letivo.

6- o aluno oriundo de exames de certificaçăo (Exame Supletivo, Exame Online, Enem e outros) organizados por àrea, que eliminou uma ou duas áreas, poderá matricular-se na(s) àrea(s) năo concluidas, Ano por Ano;

7 . $O$ aluno que cursou as trés áreas de um Ano e nâo fol aprovado em algumas dolas, deverá matricular-éa preferencialmente, na área que o mesmo nåo obteve exito, O resultado da avaliação será por área.

8. O aluno que comprovar ter eliminado uma ou mais áreas, poderá concluir a etapa da educação bás.

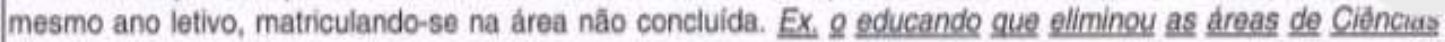

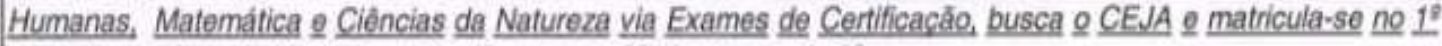
trimestre na área de Linguagens do $1^{\circ}$ ano e no $2^{\circ}$ trimetre na do $2^{\circ}$ ano.

Fonte: ROP-SEDUC (2013).

Os CEJAS buscavam reconhecer as especificidades dos sujeitos desta modalidade e dos diferentes tempos e espaços formativos, oferecendo formas diferenciadas de atendimento que compreenda a educação formal e informal integrada ao mundo do trabalho ao longo da vida. Tendo matricula e organização pedagógica em trimestre por área de conhecimento, umas propostas diferentes das demais escolas. (Bignarde,2013, p.3, OCs - MT/EJA de 2010). Pontuado a partir das narrativas abaixo:

Os Centros nasceram para atender as especificidades dos Jovens e Adultos nos tempos e espaços diferentes então foi implantado este formato para atender todos da modalidade que não tinham condições frequentar em outro horário. Por exemplo, no CEJA a oferta de ensino acontecia nos três períodos de manhã, de tarde, de noite. As pessoas que não poderiam frequentar a tarde e à noite iriam de manhã. A tarde a gente tinha um público bem especifico das senhoras e das mamães que elas levavam as crianças para a escola e depois iam estudar. (Professora Área De Ciências Da Natureza Ceja Antonio Casagrande,2020). 
(...) A princípio o CEJA, a matrícula era trimestral e cada trimestre era uma área, linguagens, ciências da natureza e matemática, a gente trabalhava estas duas juntas como sendo uma só, e a área de humanas. E o aluno, a cada trimestre estudava uma área, como se fosse, 1 ano letivo. E aí, ele tinha que fazer todo aquele processo, de matricula novamente e passava para a próxima área, então trimestralmente era feita matricula e o fechamento do ano letivo com os resultados das áreas especificas que ele queria fazer. Isso permitia ao aluno, por exemplo, fazer dois ou 3 trimestres que ele precisasse fazer de linguagens e poderia estudar o ano inteiro linguagens para depois mudar de área. Isso dava uma flexibilização, nesses acessos, ele não precisava necessariamente estudar todas as áreas seguidas. O aluno poderia fazer de acordo com a necessidade dele, de acordo com disponibilidade dele e das vagas. (...) (Professora Área De Linguagens Ceja Professora Almira,2020).

Figura 3 - Imagem de matriz curricular.

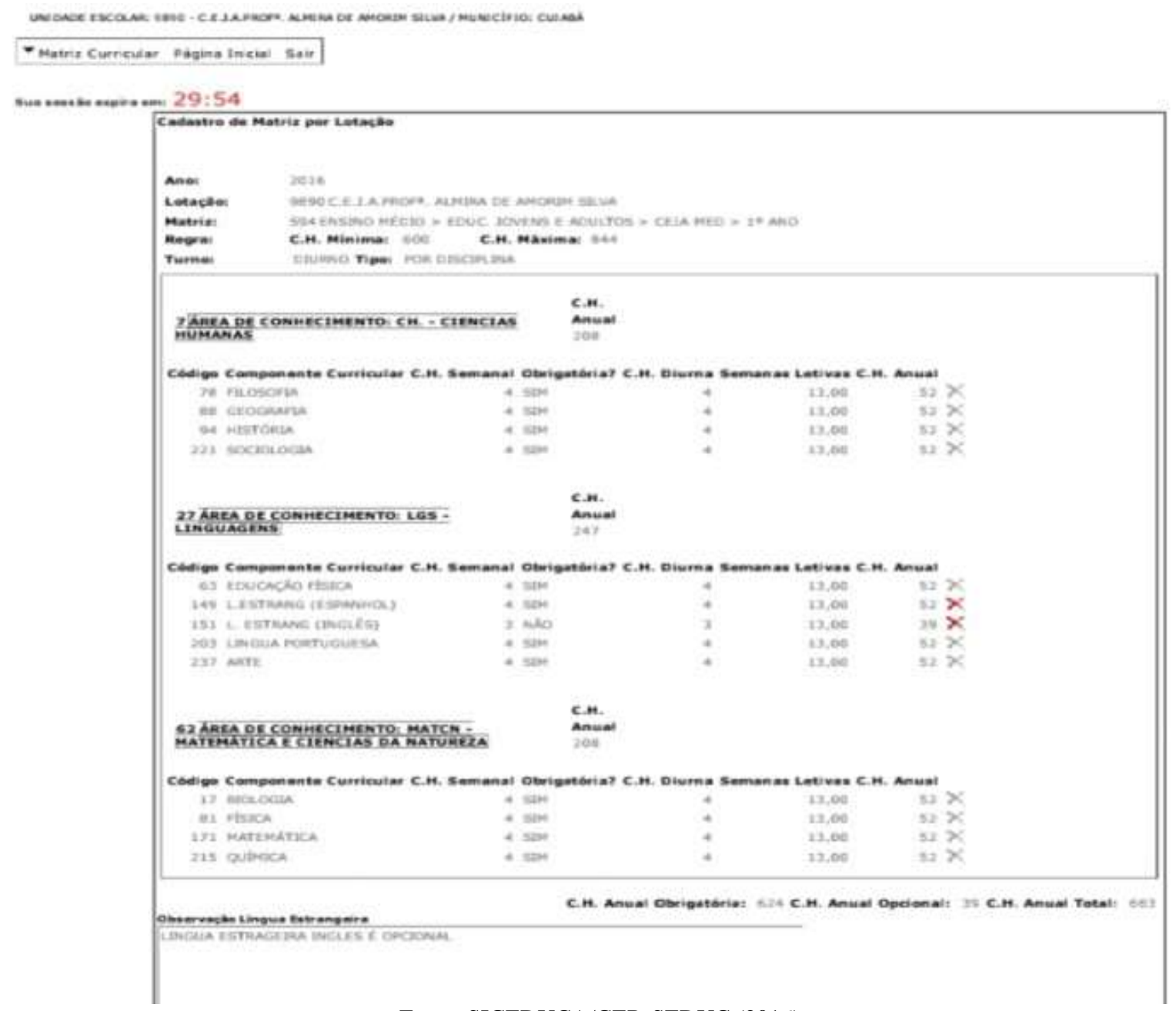

Fonte: SIGEDUCA/GER-SEDUC (2016).

Nestas narrativas e imagens de documentos podemos apontar conforme Vasconcelos (2014), que as memórias por sua vez são remetidas ao grupo, onde as lembranças são disponibilizadas de várias formas. Para Halbawchs (2004), elas podem ser reconstruídas com ajuda de dados emprestados do presente com destaque as situações e processos de ensino ocorridos em determinado tempo e lugar, sendo necessário considerar a complexidade relacionada não só a educação em geral, mas, principalmente a proposta pedagógica em estudo. Possibilitando ao aluno fazer sua matrícula na modalidade presencial por área de conhecimento.

Como também o CEJA ofertava para aqueles egressos dos exames supletivos, que para concluir os estudos faltava cursar uma ou duas disciplinas, a matricula nesses componentes. Permitindo, assim, aos educandos percorrer trajetórias de aprendizagem não padronizadas. (Bignarde, 2013). 
Contexto destacado na OCDCE:

Os CEJAS trazem aos educandos da modalidade um novo sentido de educação que propicie tempos e espaços que respeitem as especificidades de cada um. Nos Centros, cada educando tem a possibilidade de realizar seus estudos de acordo com a possibilidade que melhor que convém. (...). Tendo como cunho pedagógico a coletividade. Destacandose então, os momentos desta construção: elaboração de caminhos comuns de Projeto Político Pedagógico, as Matrizes Curriculares. (SEDUC, 2010).

Uma proposta elaborada a partir das necessidade levantadas no ano de 2007, quando a SEDUC instituiu uma Comissão Interinstitucional no Estado que não foi apenas uma proposta escrita por alguns especialistas em gabinete no atendimento à demanda reprimida, mas a construção de um coletivo que se desafiava ao novo, eles originaram-se da prática democrática por meio do trabalho coletivo, num processo gradativo iniciado com 5 (cinco) centros: Paulo Freire que depois tornou-se José de Mesquita, professora Almira Amorim e Cesário Neto, em Cuiabá; Licínio Monteiro, em Várzea Grande e Alternativo, em Juína.

De acordo com Bignarde (2013), nas orientações da comissão interinstitucional do Decreto ${ }^{\circ}$ 1.164/08-SEDUC/MT, publicado no Diário Oficial de 12/02/2008, os primeiros CEJAS seriam criados para que tivesse uma experiência na oferta da Educação de Jovens e Adultos e que já pudessem de imediato, por meio de um redimensionamento, ofertar exclusivamente a modalidade.

O enfoque de ensino deve buscar bem-estar e empenho do aluno por aquilo é considerado como importante de se aprender, não esquecendo quem são os educandos da EJA. As instituições de ensino e as relações que os indivíduos mantém com elas podem ser pensadas a partir de diversos ângulos e o pressuposto de que o CEJA é um lugar de memórias e identidades, em função das suas características históricas e relacionais.

Se por um lado, os centros de EJA sejam vistos como espaço de concentração da modalidade, no outro, a diversidade presente no público jovens, adultos e idosos tiveram um ensino que contava com uma estrutura administrativa pedagógica que propiciou tempos e espaços flexíveis por meio do currículo, calendário, metodologia, formação continuada, praticas educativas e professores com disponibilidade para a proposta. Este processo os critérios foram definidos, por meio de portaria específica, para o professor que fosse atuar nos Cejas tivesse identificação com a EJA, compromisso e fosse valorizado. (SEDUC, 2014).

Dessa forma, foi definido que o professor para trabalhar no Ceja precisaria da jornada única, isto é, carga horária de 30 (trinta) horas semanais para professores efetivos e/ou contratados, sendo 20 horas em sala e 10 de horas atividades. Com esta estrutura no quadro pessoal, foi possível elaborar uma proposta diferenciada para a EJA. (Portaria No 354/12/GS/Seduc/MT).

Os centros de EJA surgem no momento em que o Estado de Mato Grosso, bem como o cenário nacional em relação a modalidade apresenta dados preocupantes no ano de 2007, que segundo documentos é um período que precisa ser lembrado, já que havia demanda reprimida na oferta de educação para jovens e adultos, pois não havia um real projeto político de Estado com vista a organizar o atendimento desse público que deveriam ser vistos como pessoas de direitos. Sendo, necessário instituir uma política que fosse capaz de atender a essa demanda, observando características que contemplassem a flexibilização dos espaços e tempos, priorizando a diversidade de jovens e adultos. (SEDUC, 2014).

Assim, no ano de 2007, a secretaria de Estado de Educação por meio da equipe de Gerência de Educação de Jovens e Adultos (GEJA), atualmente Coordenadoria de Educação de Jovens e Adultos (CJA), iniciou o diálogo com os movimentos sociais na busca de atender a problemática dos jovens e adultos mato-grossenses para a elevação de escolaridade. Embora o Sistema Estadual de Ensino possuísse uma legislação avançada, as escolas que ofertavam a EJA permaneciam rígidas e não atendiam a maior parte das necessidades dos adultos, como horários de atendimento flexíveis, diferentes tipos de oferta, entre outras coisas. 
Para Bosi (1994, p. 9) a memória permite a relação do corpo presente com o passado e ao tempo, interfere no processo 'atual' das representações, por meio dela, o passado não só vem à tona das águas presentes, misturando com as percepções imediatas, como também empurra, mexe estas últimas, ocupando o espaço todo da consciência. Destacado por Julia (2001, 34), como um inventário sistemático destas práticas, período por período, constituindo um campo de trabalho efetivamente interessante, pois permite compreender as modificações, frequentemente insensíveis, que surgem de geração em geração.

A situação que se tinha retratada era a descontinuidade de políticas de atendimento aos jovens e adultos. A SEDUCMT constituiu uma Comissão de Redimensionamento para pensar ofertas diferenciadas para a modalidade. Para tanto, procurou-se valorizar as experiências exitosas existentes dentro do sistema estadual de ensino, bem como, conhecer as iniciativas de outros estados.

Segundo narrativa de memória:

Antes da implantação do CEJA, eu me lembro que trabalhava com regime, como supletivo. Num período semestral, os alunos estudavam por semestre. E eles faziam duas turmas por vez, sétima e oitava, fazia em 1 ano, não lembro direito, tipo supletivo. E ele era muito parecido com sistema regular, com exceção do fato de ser acelerado. Me lembro que na época os professores não eram exatamente treinados para trabalhar com a educação de jovens e adultos. Foi bem quando comecei a trabalhar, então não tinha aquela, a preocupação da escola em semana pedagógica, em focar na EJA e suas especificidades. Éramos professores que dava aula durante o dia para crianças, adolescentes e a noite fazia um plano mais adaptado, não diria nem adaptado, mas, acelerado para educação de jovens e adultos. E os treinamentos da escola, em geral eram voltados para o público diurno. A EJA ficava no noturno, e era mais uma complementação de carga horária, e agente trabalhava quase que as mesmas coisas, quase que do mesmo jeito que trabalhava com as outras turmas, com diferença de que precisávamos fazer tudo mais rápido, acelerado, então fazíamos uma reduzida e enxugada no conteúdo. Mas, não era algo pensado, especifico para a EJA. (Professora Área De Linguagens Ceja Almira De Amorim Silva,2020).

Exemplo disso foram os NES (Núcleos de Estudos Supletivos) e NEP (Núcleo de Educação Permanente), implantados em Mato Grosso na década de 80 como uma política pública para EJA, tendo como finalidade proporcionar escolarização por meio de ensino supletivo, a jovens e adultos trabalhadores que não haviam tido condições de estar na escola e concluir o ensino básico. (BOGNAR, 2019).

A proposta pedagógica que hoje encontra-se em investigação pretendia conforme registros escritos e narrativas de participantes da pesquisa reduzir problemas de negação ao acesso às aprendizagens necessárias para inserção no mundo do trabalho. Buscando valorizar e garantir direitos educativos a esses estudantes que têm auxiliado a construção de riquezas do nosso País e, em particular, do nosso Estado. Com isso, se espera maior participação qualificada desses estudantes nas políticas sociais e econômicas

Havia 25 CEJAS distribuídos em Mato Grosso criados para atender às diversidades educacionais do referido público em suas especificidades. A proposta permitia na prática, que jovens e adultos retornassem à vida escolar ao possibilitar tempos e espaços flexíveis com uma estrutura física concreta, com organização pedagógica própria e de identidade para o jovens e adultos e tem como principal característica o respeito às trajetórias de vida de cada educando, uma política de educação popular, construída coletivamente por aqueles que direta ou indiretamente estiveram envolvidos com a educação de jovens e adultos em Mato Grosso. Sendo deste modo, resultado de sonhos e compromisso político dos educadores e demais sujeitos da EJA tendo seu impulso em 2008 (SEDUC, 2014).

Inicialmente esses espaços foram não somente de identidades para a educação de jovens e adultos, como também uma proposta pedagógica que tinha como principal característica o respeito às diferentes trajetórias de vida do público atendido. Os documentos coletados e analisados como: a agenda (2012), do CEJA Antônio Casagrande, PPPs - Projetos Políticos Pedagógicos (2014), da instituição mencionada e Professora Almira de Amorim Silva (2015), a proposta curricular para a EJA 
do Ceja elaborados conforme as OCDE (2010), Regra de Organização Pedagógica (ROP, 2013), produzidas pela Seduc, que se destaca o estudo nas três áreas de conhecimento: linguagem, humanas e ciências da natureza e matemática.

De acordo com Veiga (2001), o PPP um documento que tem por função organizar o ambiente escolar caracterizando as suas intenções futuras e reconhecendo a sua comunidade. Assim, o projeto do CEJA Antonio Casagrande (2013, p. 23), esteve previsto, a organização dos conteúdos de temas e subtemas geradores desenvolvidos por meio de estudos de texto, produções, atividades variadas, ofertando um currículo interdisciplinar, contextualizado com os princípios pedagógicos norteadores da Educação Básica e fazendo com que os jovens e adultos possam ampliar seus conhecimentos sobre o mundo que os cercam e a vivencia do seu dia-a-dia.

Os assuntos trabalhados em 2009 e 2010, organizados da seguinte maneira: sua identidade "QUALIDADE DE VIDA" e como fenômenos: Meio Ambiente, Trabalho, Educação e Saúde e Diversidade Cultural, em que é trabalhada a interdisciplinaridade nas áreas de Conhecimento, representada na imagem da mandala utilizada para simbolizar a organização da proposta pedagógica curricular, desenvolvidas no Ceja Antônio Casagrande (PPP - CEJA ANTONIO CASAGRANDE, 2013).

Figura 4 - Imagem da mandala mandala utilizada para simbolizar a organização da proposta pedagógica curricular.

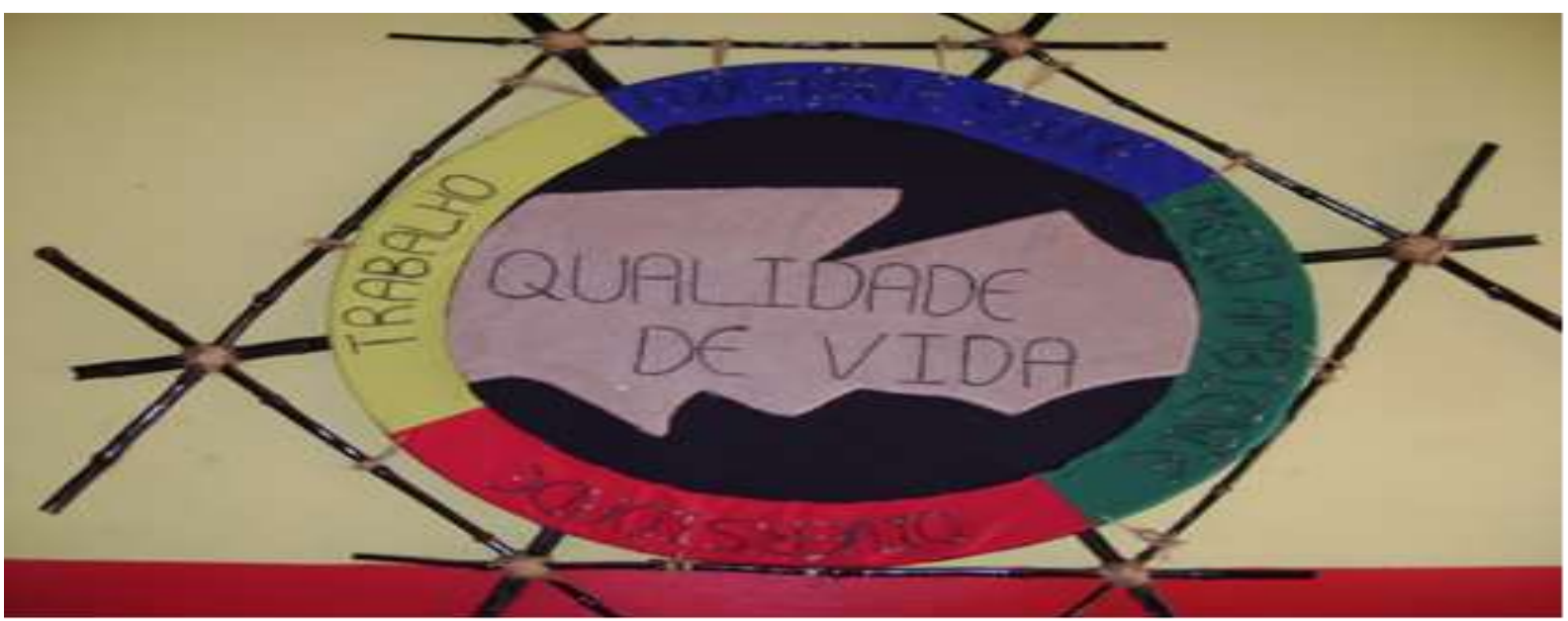

Fonte: Projeto Político Pedagógico CEJA Antonio Casagrande (2014).

O processo ensino-aprendizagem buscava o conjunto pela observação, discussão e planejamento. Propiciando as áreas de conhecimento se entrelaçarem em um único caminho para reduzir as dificuldades. Uma vez que a proposta visava o trabalho coletivo, a partir das necessidades, também momentos individuais previstos para atingir os objetivos desejados.

Algo também destacado na narrativa abaixo:

Os Centros de Educação de Jovens e Adultos e a Educação de Jovens e Adultos nasceram para atender as especificidades dos Jovens e Adultos nos tempos e espaços diferentes implantando com este formato para atender este público que não puderam frequentar em outro horário. Por exemplo nos CEJAS o atendimento era nos três períodos de manhã de tarde de noite. As pessoas que não poderiam frequentar a tarde e à noite iam de manhãa, sendo que tarde tínhamos um público bem especifico das senhoras e das mamães que levavam primeiro as crianças para a escola e depois vinham para o CEJA estudar. A noite o público predominante era trabalhador embora existisse outras especificidades. Nesta organização pedagógica diferente veja bem ele poderia se por um acaso ele não conseguisse concluir o ano todo ele tinha uma garantia porque a oferta era trimestral cada trimestre ele contemplava uma área do conhecimento e ele não perdia ele concluísse por acaso alguma eventualidade ele não conseguisse permanecer na escola ele não perderia o que ele já teria feito. Algo que era colocado na proposta como uma função reparadora que prevista no Parecer 11/2000. (Professora Ceja Antonio Casagrande, 2020). 
Este parecer mencionado na narrativa se ocupava das diretrizes da EJA, onde definia-se as três funções da modalidade, dentre elas: a reparadora que significa não só a entrada no ciclo dos direitos civis, pela restauração de um direito negado ao mesmo tempo, como uma oportunidade concreta de presença de jovens e adultos na escola e uma alternativa viável em função das especificidades socioculturais destes segmentos para os quais se espera uma efetiva atuação das políticas sociais. É por isso que a EJA necessita ser pensada como um modelo pedagógico próprio. (PARECER Nº11 /2000,7 CNE/CEB).

Ademais, a função equalizadora conforme o documento citado, seria a reentrada no sistema educacional dos que tiveram uma interrupção forçada seja pela repetência ou pela evasão, seja pelas desiguais oportunidades de permanência ou outras condições adversas. Enquanto que a tarefa de proporcionar a todos a atualização de conhecimentos por toda a vida é a função qualificadora. (PARECER Nº11/2000,7 CNE/CEB).

As propostas pedagógicas do CEJA seguem estas funções que estão previstas em vários documentos elaborados pela SEDUC entre os anos de 2008 a 2016. A OCDE (2010, p. 214), destaca que os centros tinham como intencionalidade propor um novo sentido para a EJA em Mato Grosso, ao disponibilizar em sua composição de ensino, tempos e espaços, onde cada educando teve a oportunidade de realizar seus estudos conforme a sua conveniência.

Sua estrutura pedagógica apresentava várias formas de atendimento, afim de favorecer múltiplas possibilidades de acompanhamento e intervenção pedagógica para os educandos, como: aulas na turma de origem, atendimento individualizado em plantões, oficinas pedagógicas e aulas culturais. (OCDE, 2010, p. 214-215). Neste sentido a professora da área de ciência da natureza e matemática do CEJA Antonio Casagrande, (2020) destaca:

\begin{abstract}
A prática de ensino dentro dos CEJAS era bem diversificada, fazíamos uma distribuição do tempo, onde os estudantes tinham as aulas em sala de aula presenciais, oficinas pedagógicas, sábados culturais, e também existia os plantões. $\mathrm{Na}$ qual eles poderiam vir num outro horário para estar tirando suas dúvidas alguma dificuldade de aprendizagem tendo o professor como um apoio para que o educando pudesse desenvolver as atividades que ele não conseguiu desenvolver naquele tempo em sala de aula. As oficinas pedagógicas era uma forma também de aprendizagem, porém com uma prática uma metodologia diferente, utilizando algum tema para concluir aquela aprendizagem já pré organizada. A exemplo disso são os temas presentes na imagem da mandala já apresentada neste estudo e a construção dela aconteceram em várias oficinas realizadas no CEJA Antonio Casagrande.
\end{abstract}

Tendo como metodologia utilizada conforme a agenda institucional (2012) e PPP - CEJA Antonio Casagrande (2013, p. 56), a problematização de Charles Meguerez (1970) e Paulo Freire (1993), destacando o tema gerador e impulsionando a troca de saberes através do diálogo que respeita as diferenças de cada sujeito em suas visões de mundo. Tendo o educador o papel de mediador entre o saber já construído por cada educando com o saber em processo de construção intersubjetiva a partir da discussão em grupo.

Além de privilegiar o desenvolvimento coletivo, este método parte do princípio de que educandos e educadores devem ser ativos e agentes de transformações sociais. Sendo representada pelo Método do Arco, partindo do princípio da realidade do aluno. 


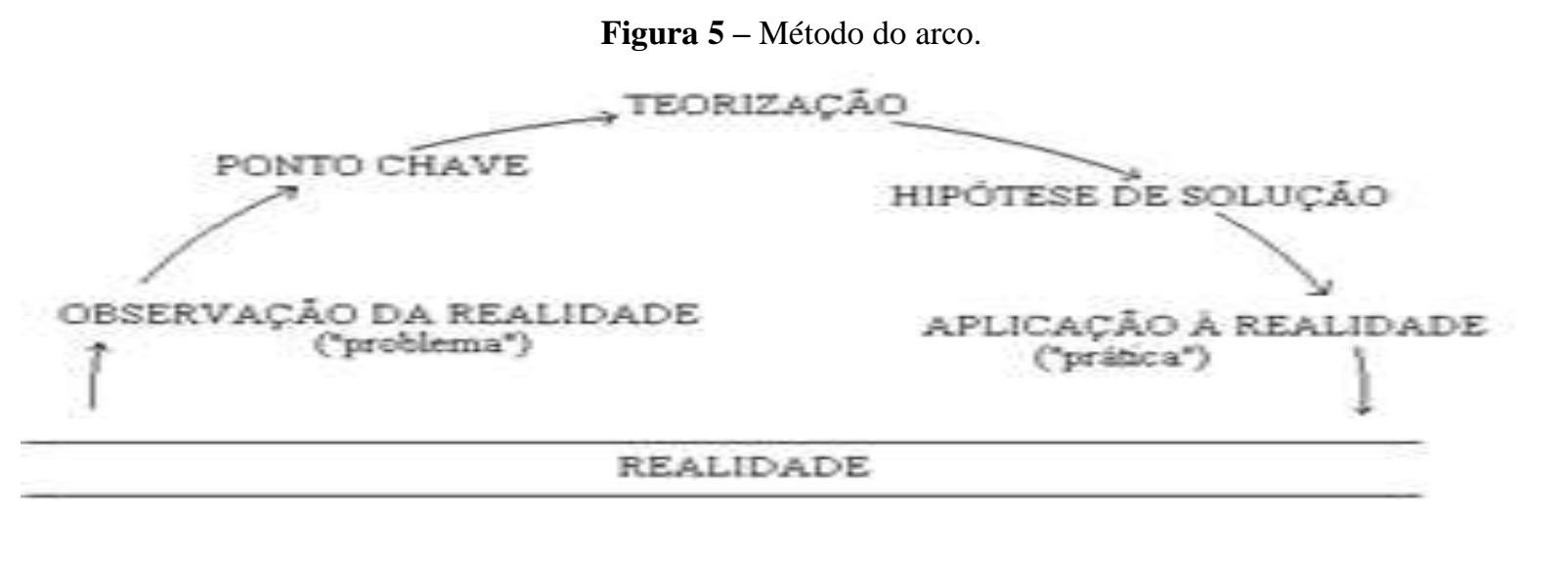

Fonte: Projeto Político Pedagógico CEJA Antonio Casagrande (2014).

E considerando os seguintes passos:

1. Observação da realidade: Pesquisa sócio-antropológica conhecendo o educando. Nesse primeiro momento o aluno é conduzido e expressar suas percepções pessoais tendo como foco principal o levantamento de problemas.

2. Pontos chave: $\mathrm{O}$ segundo momento, mediante levantamento dos problemas identifica-se vários pontos chaves, partindo daí, prioriza-se o de maior importância e que contribua para a elaboração dos conteúdos significativos.

3. Teorização: No terceiro momento, o papel do professor é muito importante, pois além de estimular os alunos a participar ativamente da construção do conhecimento científico através de leitura, vídeos, revistas, palestras, entre outros, para que os mesmos possam construir seus próprios conceitos a respeito dos temas debatidos.

4. Hipóteses de solução: Confrontada a realidade com a teorização, o aluno se vê naturalmente movido a uma quarta fase, a formulação de hipóteses para o problema em estudo. Neste momento os alunos elaboram as possíveis soluções para os problemas, ou seja, o aluno usa a realidade para aprender com ela ao mesmo tempo em que se prepara para transformá-la.

5. Aplicação à realidade: Na última etapa, o aluno pratica e fixa as soluções que o grupo identificou como as mais viáveis e aplicáveis. Aprende a generalizar o aprendido para utilizar em situações diferentes e distingue em que circunstâncias não é possível ou conveniente a aplicação, sabendo escolher.

(Charles Maguerez, 1970).

De acordo com os documentos analisados, o arco enquanto método representa uma propositura ao educador de refletir e colocar em prática os temas escolhidos e abordados no Ceja Antonio Casagrande. Em que o educador deve ter sempre em mente que o seu papel é o de agente de transformação social e como tal, pode, pela educação, ser o mediador e construir relações de confiança para que o educando possa perceber-se e viver, como ser social. (PPP - CEJA ANTONIO CASAGRANDE, 2013, p. 56), segundo Braz (2016), o olhar desta instituição representado na escrita deste documento e presente em narrativas de memórias.

No exercício constante para que tivesse envolvimento coletivo, partindo do princípio de que o aluno é um ser ativo e agente transformações sociais, buscando para os problemas, soluções originais e criativas.

Como ação que justificava o diálogo e coletividade vivenciada, encontramos a seguinte narrativa:

No CEJA tinha como coisa muito legal, de formação de professor, eu lembro que no primeiro ano de formação do CEJA, que mudou a minha visão, era justamente a formação que recebiamos, a gente tinha além da sala de educador que era um formato completamente diferente da que é agora do curso do CEFAPRO. Tínhamos o grupo de estudo, na nossa hora atividade, e esse grupo de estudo estudávamos exatamente as necessidades que víamos no dia a dia. Ai eu comecei a entender que esse aluno é um adultos que chega com história, é um aluno que chega com um conhecimento prévio, muitas vezes, aquilo que estou falando para ele, ele já sabe, só que ele sabe de uma outra forma, sabe com outro nome, então por exemplo, um professor de Matemática ele pode ensinar fração para uma cozinheira que ela não 
sabe o que é fração, mas, se ela está lá, duas xicaras e meia de açúcar, ela sabe o que é . Então essa compreensão eu vi a ter a partir desses cursos, a partir desse contato coma educação de jovens e adultos. (Professora Área de Linguagens - Ceja Professora Almira).

Salientamos que o processo ensino-aprendizagem nesta organização pedagógica do CEJA entre os anos de 2008 a 2016 buscava a interdisciplinaridade de forma que as áreas se entrelacem em um só caminho, que a postura a ser adotada quanto a metodologia aplicada terá como funções fundamentais, a busca dos conhecimentos que permitam o crescimento pessoal, o acesso a outras fases de estudos e o prosseguimento destes em outros níveis de escolaridade. (PPP - Professora Almira de Amorim Silva, 2015).

Para regras de funcionamento principalmente de escrituração no sistema SigEduca também foi criado pela SEDUC/MT, a ROP dos CEJAs (2013). Aplicada segundo o PPP - CEJA Antonio Casagrande em conformidade com os componentes curriculares e as ações desenvolvidas na Escola.

A instituição um dos locus da referida pesquisa, serve como documento dos acontecimentos passados. O CEJA armazenou parte de memória social em decorrência de seu cotidiano e de sua temporariedade. Conforme os documentos identificados compreendemos que a partir deles há uma perspectiva das impressões do presente com o passado.

Nesta identificação de fontes, teve uma significativa parceria de indicações e diálogos de leitura, fichamento e análise com a orientadora de todo o material selecionado, para posterior redação do artigo.

Conforme a narrativa abaixo:

Atender as especificidades dos sujeitos da EJA é reconhecer o papel, o lugar de cada um na nossa sociedade e dar essa oportunidade de ouvir estas vozes é trabalhar o artigo 206 da constituição diz a educação é um direito de todos é um dever e papel do estado é que a gente sempre questiona este dever e dar garantias a esses sujeitos e então é isso o meu recado e o recadinho do PAULO FREIRE onde a pessoas tem muito que aprender e ensinar, cada um tem o saber diferente que constitui o seu saber através de outros. (Professora da área de Ciência da Natureza e Matemática, CEJA Antonio Casagrande).

Para que essas experiências não se percam, especialmente porque nem sempre são sistematizadas e registradas, mobiliza-se um conceito de memória como reconstrução: evocação "de um passado visto pela perspectiva do presente e marcado pelo social, presente a questão da memória individual e da memória coletiva” (Lang, 1996, p. 35). A recuperação da memória por intermédio de autores e das documentações existentes limita-se à parcialidade da memória, o que não a invalida, mas pode restringir sua compreensão, como alertam Schueler e Magaldi (2009, p. 52).

As ações pedagógicas conforme as narrativas de professores entrevistados foram levadas em conta a necessidade de praticar inclusão, sendo esse um dos princípios da EJA, a necessidade de aprendizagem própria de cada geração e faixa etária, o que requer atividades diferenciadas. A cada trimestre o CEJA Antonio Casagrande conforme seu PPP (2013), realizava escolhas de temas geradores que se desdobram em subtemas e orientavam as ações.

Nota-se que a proposta tinha como um dos pressupostos teóricos Paulo Freire (1993), ao destacar que o tema gerador impulsiona a troca de saber por intermédio do diálogo que respeita as diferenças de cada pessoa em suas visões de mundo. Tendo o papel de gerir entre o saber já construído por cada sujeito com o saber em processo de construção intersubjetiva a partir da discussão em grupo.

Nas narrativas analisadas observamos que uma representação de luta permanente para o acesso e permanência ao conhecimento formal e informal, principalmente em relação à educação escolar pautada na emancipação do sujeito para implantação dos CEJAS para a modalidade e permanência da proposta inicial desenvolvida entre os anos de 2008 a 2016. 
Assim, como Chilante; Noma (2009, p. 229), a EJA se constitui numa luta para o acesso a esses conhecimentos, principalmente por ser tratada como dívida social a ser reparada, que deveria assumir a tarefa de estender a todos o acesso e o domínio da escrita e da leitura como bens sociais, seja na escola, ou fora dela.

Percebemos neste processo de análise das entrevistas realizadas, principalmente em relação aos estudantes o quanto a memória seja seletiva e a lembrança diz respeito ao passado, mas ao mesmo se atualiza sempre a partir de um ponto presente. As memórias não são falsas ou verdadeiras, simplesmente contam o passado através dos olhos de quem as vivenciou (Goldenberg, 2018, p. 61), também pode ser segundo Halbwachs (2013), um fenômeno social da expressão tanto individual quanto coletiva, tendo aspectos positivos e negativos.

Estudei no CEJA Antônio Casagrande entre os anos 2008 a 2011, pois, neste período estudava sétima e oitava série ao mesmo tempo, não existia o nono ano ainda. Em seguida conclui o ensino médio, pois não quis fazer provas classificatórias. Porque eu queria aprender devido a metodologia, o ensino os professores serem muito bons lá. Eu gostava muito de estudar lá, parei quando jovem. E voltei, com dezessete anos, mas, eu gostava muito de estudar lá. Nunca estudado numa escola com essa metodologia, de trimestre por área de conhecimento, foi a primeira e única vez. Saí de lá, direto pra Universidade, com a bolsa do ProUni 100\% (por cento). (Estudante, Ceja Antonio Casagrande).

Segundo Chartier (2002, p. 73), inicialmente, o trabalho de classificação e de recorte que produz as configurações intelectuais múltiplas pelas quais a realidade é contraditoriamente construída pelos diferentes grupos que compõem uma sociedade. Na sequência as práticas que visam reconhecer uma identidade social, exibindo um jeito próprio de ser no mundo, a significar simbolicamente um estatuto e uma posição; formas institucionalizadas e objetivas em decorrência das quais representantes de instancias coletivas marcam de modo visível a existência de um grupo.

\section{Considerações Finais}

Neste recorte apresentamos resultados parciais de parte das análises de documentos e entrevistas realizadas com professores e estudantes que estiveram envolvidos na organização pedagógica em trimestres por área de conhecimento implantada nos CEJAS em Mato Grosso no ano de 2008 e que permaneceu até o ano de 2016, para constituição da memória coletiva desta proposta de ensino. No processo de investigação nota-se a existência de vários documentos produzidos tanto pela SEDUC em relação aos CEJAS, quanto aqueles elaborados pelas instituições lócus desta pesquisa.

Encontramos dificuldades em selecionar ou priorizar um documento em detrimento do outro, no entanto, a escolha aconteceu a partir daqueles que apresentavam dados da proposta em estudo como: calendário, matriz curricular e metodologia evidenciados nos documentos apresentados na estrutura do artigo. Representando lembranças de tempos e espaços flexíveis criados no CEJA, diferente das demais escolas que ofertam a EJA e ainda pontuando eles foram criados em Mato Grosso para constituir identidade própria a modalidade, ofertando configurações diferenciadas de estudo que relacionassem a educação formal e informal ao mundo do trabalho e ao longo da vida, reconhecendo as especificidades do público e dos diferentes tempos e espaços formativos.

Também evidenciamos nas narrativas de professores que os Centros nasceram para atender as especificidades dos Jovens e Adultos nos três períodos de funcionamento das unidades escolares. Diferenciando daquilo que já existia, pois na maioria das vezes, a EJA é atendida somente no período noturno. E ainda apresentando um outro público, como é o caso do período vespertino do CEJA, em que tinha um público bem especifico de senhoras e mamães que elas levavam as crianças para a escola e depois iam estudar. 
Enquanto os estudantes em suas narrativas evidenciaram que a proposta investigada contribuiu para eles retornassem aos estudos, pois, o enfoque de ensino era buscar as necessidades do aluno num exercício de tornar a escola um espaço significativo. Tanto os dados presentes nos documentos analisados como os selecionados nas entrevistas realizadas evidenciam que o ensino para EJA nos centros contava como uma estrutura administrativa pedagógica voltada para as especificidades da modalidade, sendo partes das lembranças e reconstruções de professores e estudantes que estiveram neste tempo pesquisado.

Assim, evidencia-se que os dados analisados potencializam a memória coletiva, embora ainda seja necessária uma continuidade nas discussões, principalmente em relação as muitas mudanças e rupturas no CEJA que desconsideram o que havia sido realizado e que culminou em sua extinção definitiva no final do ano de 2020. Esta investigação busca demonstrar que os grupos sociais constroem suas narrativas com base na memória da experiência que lamentavelmente tem sido desconsiderada quando se trata elaboração e continuidade de políticas públicas educacionais.

Contudo, não se encerra aqui, mas, espera-se que o artigo possa colaborar com estudos existentes essencialmente sob viés da memória coletiva. Tendo em vista suas diversas extensões, que estimula novos olhares e investigações, há nela riquíssimas informações a investigar e que não temos a pretensão de esgotar nesse recorte de estudo.

Posto as diversas possibilidades no campo teórico-científico no que tange a exploração, desdobramento e continuidade do assunto em tela, uma vez, como já mencionado, não se dá por findado e/ou concluído, visto a presença de pressupostos e propósitos que corroboram para isso (fato social, grupos sociais, momentos vividos, experiências), e assim propor novos caminhares e/outros rumos para o estudo apresentado.

\section{Referências}

Bignarde, G. K. (2013). A Produção da Política de Constituição dos CEJAS. Espaço do Currículo, v.6, n.3, p.474-483 -144, set/dez.

Bognar, I. \& Ferreira, M. S. (2019). Avanços e Retrocessos na Política de Educação de Jovens e Adultos no Estado de Mato Grosso/Brasil (2008/2017) REVES-Revista Relações Sociais, Vol. 02 N. 03.

Boldarine, F. R. (2010). Representações, narrativas e práticas de leitura: um estudo com professores de uma escola pública. Dissertação (Mestrado em Educação). Faculdade de Filosofia e Ciências, Universidade Estadual Paulista.

Bosi, E. (1994). Memória e sociedade. 5. ed. São Paulo: Companhia das Letras.

Brasil. Conselho Nacional de Educação. Câmara de Educação Básica. Parecer n. 11 de 10 de maio de 2000. Institui as Diretrizes Nacionais para a Educação de Jovens e Adultos. Disponível em: http://portal.mec.gov.br/secad/arquivos/pdf/eja/legislacao/parecer_11_2000.pdf. Acesso em: 25 de agosto de 2013.

Brasil. (1988). Constituição Federal do Brasil. Brasília: Senado Federal.

Brasil. LDB. (1996). - Lei de Diretrizes e Bases da Educação Nacional - Lei n ${ }^{\circ}$ 9.394, de 20 de dezembro.

Chartier. R. (2002). À Beira da Falésia: A história entre certezas e inquietudes. Porto Alegre: Ed. Universidade. UFRGS.

Chartier. R. (2002). À Beira da Falésia: A história entre certezas e inquietudes. Porto Alegre: Ed. Universidade. UFRGS.

Chilante, N. E. F. \& Noma Kimiko, A. Reparação da dívida social da exclusão: uma função da educação de jovens e adultos no Brasil? Revista HISTEDBR On-line, Campinas, n. Especial, p 225-237, mai. 2009. <http://www.histedbr.fae.unicamp.br/revista/edicoes/33e/art14_33esp.pdf>.

Fialho, M. L. L. T. M \& Brandenburg, C. (2016) (Orgs). Educação, Memórias e Narrativas. Fortaleza: Eduece.

Freire, P. (1993). Pedagogia do oprimido. São Paulo: Paz e terra.

Goldenberg, M. (2018). A arte pesquisar: como fazer pesquisa qualitativa em Ciências Sociais. 15 a ed. Rio de Janeiro: Record.

Haddad, S., Di Pierro, M.C. (2000). Escolarização de jovens e adultos. Revista Brasileira de Educação, 14:108-130.

Halbwachs, M. (2013). A Memória Coletiva. Tradução de Beatriz Sidou. $2^{\mathrm{a}}$ ed. São Paulo: Ed. Centauro.

Lang, A. B .da S.G. (1996). História oral: muitas dúvidas, poucas certezas e uma proposta. In: MEIHY, J. C. S. B. (Org). (Re) introduzindo história oral no Brasil. São Paulo: Xamã.

Marconi, M. de A; Lakatos, E. M. (2019). Fundamentos de metodologia científica. 8. ed. São Paulo: Atlas.

Marconi, M. de A. Lakatos, E. M. (2021). Metodologia do Trabalho Científico. 9 9a. ed. São Paulo: Atlas. 
Research, Society and Development, v. 10, n. 9, e55310918419, 2021

(CC BY 4.0) | ISSN 2525-3409 | DOI: http://dx.doi.org/10.33448/rsd-v10i9.18419

Mato Grosso (2010). Secretaria De Estado De Educação. Orientações Curriculares: Diversidades Educacionais. Cuiabá: Defanti, 214.

Mato Grosso (2013). Secretaria de Estado de Educação. (ROP) - Regras de Orientação Pedagógica dos CEJAS por área de conhecimento.

Muylaert, C. J. et al. (2014). Entrevistas narrativas: um importante recurso em pesquisa qualitativa. Revista da Escola de Enfermagem da USP, vol. 48, n. spe2, São Paulo, dez.

Nora, P. (1993). Entre memória e história: a problemática dos lugares. Trad. Yara Khoury. Projeto História, São Paulo: PUC-SP, n. 10, p. 7-28, dez.

Pereira, J. E. D.\& Fonseca, M. C. F. R. (2001). Identidade Docente e Formação de Educadores de Jovens e Adultos. Porto Alegre, Educação \& Realidade, vol. 6, n. 2, p. 51-73, jul./dez.

Ribeiro, V. M. A. (1999). Formação de Educadores e a Constituição da Educação de Jovens e Adultos como Campo Pedagógico. Educação e Sociedade, Campinas, v. 20, n. 68, p. 184-201, dez.

Schueler, A. F. M \& Magaldi, A. M. B. de M. Educação escolar na primeira república: memória, história e perspectiva de pesquisa. Tempo, Niterói, v.13, n.26, 32-55, 2009

Silva, J. C \& RUCKSTADTER, F. M. M. (2016). Centro de Memória na Escola: Uma Contribuição para a Construção do Conhecimento Histórico In: PARANÁ. Secretaria de Estado da Educação. Superintendência de Educação. Os Desafios da Escola Pública Paranaense na Perspectiva do Professor PDE: Produção Didático-pedagógica, 2013. Curitiba: SEED/PR., V.2.

Simson Von, O. https://ihggcampinas.org/2018/08/17/o-direito-a-memoria/\#comments Acesso em: 24 de dez 2021.

Teixeira Aguiar, M. L. (2015). XXVII Simpósio Nacional de História, Lugares de Historiadores Velhos e Novos Desafios. A Escola como Lugar de Memória. Florianópolis.

Veiga, I. P. A. (2001). (Org.). As Dimensões do Projeto Político-Pedagógico. Campinas, 4. ed. São Paulo: Papirus. 